\title{
Comparison of MRI, CA-125 and HE-4 in determining the depth of myometrial invasion in cases with endometrial cancer
}

\author{
Samican Özmen ${ }^{1}$, Sefa Kurt ${ }^{1}$, Orkun Ilgen ${ }^{1}$, Funda Barlik Obuz ${ }^{2}$, Ali Riza Sisman ${ }^{3}$, \\ Meral Koyuncuoglu ${ }^{4}$ \\ ${ }^{1}$ DOKUZ EYLUL UNIVERSITY SCHOOL OF MEDICINE, DEPARTMENT OF GYNECOLOGY AND OBSTETRICS, IZMIR, TURKEY \\ ${ }^{2}$ DOKUZ EYLUL UNIVERSITY SCHOOL OF MEDICINE, DEPARTMENT OF RADIOLOGY, IZMIR, TURKEY \\ ${ }^{3}$ DOKUZ EYLUL UNIVERSITY SCHOOL OF MEDICINE, DEPARTMENT OF BIOCHEMISTRY, IZMIR, TURKEY \\ ${ }^{4}$ DOKUZ EYLUL UNIVERSITY SCHOOL OF MEDICINE, DEPARTMENT OF PATHOLOGY, IZMIR, TURKEY
}

Objective. Endometrial cancer is one of the most common malignancies in the world. There is no effective screening method used for predicting the clinical stage of the disease in the preoperative period and to plan the surgical procedure. The aim of this study is to compare the serum levels of CA-125 and HE-4 with MRI, to evaluate their ability to predict the depth of myometrial invasion in patients diagnosed with endometrial cancer, and to compare the specificity between these two tests. Materials and Methods. This prospective study was conducted at Dokuz Eylul University Faculty of Medicine, Department of Obstetrics and Gynecology, between February 2019 and February 2020. A total of 47 cases were included in the study. The cases were evaluated with MRI preoperatively to determine the extent of the disease. Preoperative serum CA-125 and HE4 levels were measured by ELISA method and compared, and the superiority of the tests to each other in determining the depth of myometrial invasion was evaluated. Results. In patients with endometrioid cancer, preoperative CA-125 and HE-4 levels were found to be higher if the myometrial invasion is $>50 \%$ and lymphovascular space invasion is positive, and the difference was statistically significant. A cut-off of $7,05 \mathrm{U} / \mathrm{ml}$ for CA-125 could detect the deeper myometrial invasion with a sensitivity of $83 \%$ and a specificity of $52 \%$, respectively. A cut-off of $94,25 \mathrm{pmol} / \mathrm{L}$ for HE-4 could detect deeper myometrial invasion with a sensitivity of $75 \%$ and a specificity of $56 \%$, respectively. The sensitivity of MRI in determining the depth of myometrial invasion was $87,1 \%$, and the specificity was $86,7 \%$. Conclusions. MRI, HE-4 and CA-125 were found to be valuable tests in predicting the extent of the disease and planning the surgical treatment. All three methods successfully predicted the myometrial invasion depth of the disease. The success rates of the tests in predicting the depth of myometrial invasion were MRI, HE- 4 and CA-125, respectively. HE-4 and CA-125 could not reach the sensitivity and specificity of MRI in determining the depth of myometrial invasion at any cut-off value. However, it was proved in this study that they can play important roles as simpler and more cost-effective tests in determining the extent of the disease, able to contribute to surgical planning during preoperative evaluation.
\end{abstract}

Category: Original Research Paper

Received: February 02, 2021

Accepted: April 08, 202

Published: May 10, 2021

\section{Keywords:}

endometrial cancer, magnetic resonance imaging, HE-4, CA-125

* Corresponding author:

Samican Özmen,

Dokuz Eylul University School of Medicine, Department of Gynecology and Obstetrics, Mithatpasa Cd. No:1606, 35340 Balcova, Izmir, Turkey

E-mail: samicanozmen@hotmail.com

\section{Introduction}

Endometrial cancer is the most common gynecological malignancy in high-income countries. Considering the entire world population, it is the second most common type of cancer after cervical cancer [1]. Each year, 288,000 new cases and 74,000 deaths have been reported in Europe and the United States due to endometrial cancer [2]. The average age of incidence of the disease is 62 years. The most common symptoms in patients are menometrorrhagia in the premenopausal period and vaginal bleeding in the postmenopausal period. The gold standard diagnostic method in endometrial cancer is an endometrial biopsy. The sensitivity of biopsy for diagnosis is $90 \%$ [3]. Apart from endometrial biopsy, the diagnosis of endometrial cancer can be made incidentally in the presence of abnormal cervical cytology or by suspecting endometrial pathologies during imaging methods. The imaging method with the highest sensitivity and specificity for endometrial cancers is pelvic magnetic resonance imaging (MRI) [4]. Staging is performed surgically in endometrial cancer [5]. Staging surgery includes total hysterectomy, bilateral salpingo-oophorectomy and lymphadenectomy. Surgery limited to hysterectomy and bilateral salpingooophorectomy is recommended in order to avoid complications of lymphadenectomy in early-stage disease ( $<50 \%$ myometrial invasion, $<2 \mathrm{~cm}$ tumor diameter, histologically endometrioid type grade 1 or 2 tumor, no

To cite this article: Samican Özmen, Sefa Kurt, Orkun Ilgen, Funda Barlik Obuz, Ali Riza Sisman, Meral Koyuncuoglu. Comparison of MRI, CA-125 and HE-4 in determining the depth of myometrial invasion in cases with endometrial cancer. $J$ Clin 
evidence of extension outside the uterus during surgery, no cervical involvement) [6]. Since the disease usually presents with signs and symptoms in the early stages, the prognosis of endometrial cancer is good. For this reason, there is no tumor marker specifically researched for endometrial cancer. CA-125 (Cancer Antigen-125) and HE-4 (Human Epididymis Protein-4) are among the tumor markers that have been shown to be effective in terms of endometrial cancer.

The clinical use of CA-125 is mainly in ovarian cancer. There are studies showing that the increase in serum CA125 levels in endometrial cancer may be associated with advanced-stage disease and the need for adjuvant therapy [7].

Human Epididymis Protein-4 (HE-4) was first detected in 1999 by Schummer et al. in ovarian cancer tissue [8]. In the following years, it has been shown that HE-4 may be useful in distinguishing patients with endometrial cancer from healthy patients. HE-4 is also useful in determining advanced-stage disease [9,10]. Angioli et al. showed that serum concentration of $>70 \mathrm{pmol} / \mathrm{L}$ has the highest sensitivity, specificity and positive prognostic value for endometrial cancer [11].

The aim of this study is to evaluate the capacity of MRI, CA-125 and HE-4 serum levels in predicting the depth of myometrial invasion in the preoperative period in patients diagnosed with endometrial cancer, and to determine a possible superiority between these tests.

\section{Materials and Methods}

This prospective study was conducted at Dokuz Eylul University Faculty of Medicine, Department of Obstetrics and Gynecology, between February 2019 and February 2020. The study was approved by The Ethics Committee of Clinical Research of Dokuz Eylul University (protocol number: 4594-GOA, 06.03.2019). Written informed consent was obtained from all patients. All patients who underwent surgery for endometrial cancer during the specified period were included in the study. Exclusion criteria were the patients without preoperative endometrial biopsy, patients who were not investigated by magnetic resonance imaging before surgery, patients who had previously received chemotherapy/ radiotherapy for endometrial cancer, patients with another synchronous tumor, and patients who had been previously treated in other hospitals.

The surgical staging was performed by total hysterectomy and bilateral salpingo-oophorectomy, with or without pelvic and paraaortic lymph node dissection according to the results of the frozen section. Stage of patients, histological subtype, the grade of the disease and other parameters were classified. Contrast-enhanced magnetic resonance imaging was used as the imaging method. Magnetic resonance imaging was performed by Dokuz Eylul University Department of Radiology. Imaging of the patients was obtained with Philips MR Systems Ingenia 1.5T MR imaging device (Philips Healthcare/ Philips Medical Systems B.V, The Netherlands). The contrast agent Gadoterat Meglumin (Dotarem, Guarbet İlaç Medical Malzemeleri ve Cihazlar San. Ve Tic. A.Ş) was applied as 10 ccs. T2W images were used to evaluate the depth of myometrial invasion in MR imaging. Invasion depth was calculated in post-contrast series, especially in cases where irregularities were observed in the endometrium-myometrium junction and the continuity of the endometrial line was lost. "Depth of invasion/myometrial thickness x $100 \%$ " equation was used for calculation. The evaluation was made by the same radiologist for all patients. Serum CA-125 levels were measured with RayBio Human CA125 ELISA kit, serum HE-4 levels were measured with Human HE-4 PicoKine ELISA kit. Afterward, the findings of CA-125, HE-4 and MR imaging were compared with the postoperative pathology reports. Superiority of the tests over each other was evaluated.

SPSS 24.0 was used for statistical analysis. Descriptive statistical methods (mean, standard deviation, median, minimum-maximum) and Mann-Whitney-U test were used for comparison between two groups. Kruskal-Wallis test was used for comparison of more than two groups and $\mathrm{T}$ test was used in the comparison of independent samples' average. ROC (Receiver Operating Characteristics) analysis was performed to estimate the performances of CA-125 and HE-4 markers in evaluating the depth of myometrial invasion. Cohen's Kappa test was performed to evaluate the compatibility of myometrial invasion depth in magnetic resonance imaging and the depth of myometrial invasion as a result of the final pathology. Again, Cohen's Kappa test was used to evaluate the compatibility of endometrial sampling and diagnosis type. $\mathrm{p}<0,05$ was accepted as statistically significant.

\section{Results}

A total of 47 patients who underwent surgery during the specified period were included in the study. The mean age of 47 patients was $61.7 \pm 8.4$ (range $41-79$ ). At least one comorbid disease was detected in $34(72 \%)$ of the patients. The demographic characteristics of the patients are presented in Table 1.

41 of the 47 patients were diagnosed after menopause. 39 patients were diagnosed as endometrioid type of cancer, while non-endometrioid cancers were seen in 8 patients (undifferentiated type carcinoma, mixed type carcinoma, clear cell carcinoma, serous carcinoma) (Table 2).

The frozen section was studied during the operation in 40 of 47 patients. The comparison of the results of the 
frozen section with final pathology is presented in Table 3. In 3 patients, the frozen section reported $<50 \%$ myometrial invasion. In those 3 patients, the final pathology reported that the myometrial invasion was above 50\%. Endometrial cancer was not observed in two patients as the result of the final pathology. One of these patients had hyperplasia with atypia. The other patient was cured after dilatation and curettage. Histological grades of patients were detected as follows; $65 \%$ grade $1,19 \%$ grade 2 , and $16 \%$ grade 3.32 patients were diagnosed with stage 1 disease, 7 were diagnosed with stage 2 disease and 6 patients were diagnosed with stage 3 disease (Table 4).

When all cases participating in the study are considered, the results of the ROC analysis in the evaluations made with MRI, HE-4, CA-125 and ultrasonography (USG) for more than $50 \%$ depth of myometrial invasion are shown in Table 5 and Figure 1. According to these results, when evaluating all patients regardless of endometrial cancer type, there is no procedure that significantly predicts the depth of myometrial invasion, except for MRI. The sensitivity of MRI in predicting the depth of myometrial invasion was $87.1 \%$, and its specificity was $86.7 \%$.

In Table 6 and Figure 2 are presented the ROC analysis of MRI, HE-4, CA-125 and ultrasonography, which were used to determine the depth of myometrial invasion in patients with endometrioid cancers. According to these results, CA-125 and HE-4 have been shown to be effective in predicting the depth of myometrial invasion, in addition to MRI. For ultrasonography, the area under the curve is 0,555 and this value is not statistically significant. Therefore, there is no cut-off value for endometrial thickness in ultrasonography that could help to predict the depth of myometrial invasion.
Table 1. Demographic characteristics of the patients $\mathrm{N}: 47$ $61,7 \pm 8,4$

Age (year) $2,9 \pm 1,8$

Gravida

Parity, mean

$2,2 \pm 1,4$

\section{Parity}

\begin{tabular}{|c|c|}
\hline Nulliparous & $6(13 \%)$ \\
\hline Multiparous & $4(87 \%)$ \\
\hline Nomorbidities & $13(28 \%)$ \\
\hline Yes & $34(72 \%)$ \\
\hline High Blood Pressure & 13 \\
\hline Diabetes Mellitus & 4 \\
\hline HBP+DM & 8 \\
\hline Other (OSAS, epilepsy etc.) & 9 \\
\hline Menopausal status & $41(87 \%)$ \\
\hline Postmenopausal & $6(13 \%)$ \\
\hline Premenopausal & $15,2 \pm 8,2$ \\
\hline $\begin{array}{l}\text { LMP in postmenopausal patients, } \\
\text { mean }\end{array}$ & \\
\hline Abreviations: & \\
\hline
\end{tabular}

Abbreviations: HBP, high blood pressure; DM, diabetes mellitus; LMP, last menstrual period

Table 2. The detection rate of endometrial biopsy

\begin{tabular}{|l|l|l|l|c|}
\hline \multirow{2}{*}{ Endometrial Biopsy } & \multicolumn{2}{|l|}{ Pathology, n (\%) } & $\begin{array}{c}\text { Number of patients, } \\
\text { n (\%) }\end{array}$ & p value \\
\cline { 2 - 5 } & Endometrioid & Non-Endometrioid & $2(25,0 \%)$ & $38(84,4 \%)$ \\
\hline Endometrioid & $36(97,3 \%)$ & $6(75,0 \%)$ & $7(15,6 \%)$ & $0,760(<0,001)$ \\
\hline Non-Endometrioid & $1(2,7 \%)$ & $8(100 \%)$ & $45(100 \%)$ & \\
\hline Number of patients, $\mathbf{n}(\%)$ & $37(100 \%)$ & &
\end{tabular}

Table 3. Comparison of the results of the frozen section with final pathology

\begin{tabular}{|l|c|c|c|}
\hline & Myometrial invasion $<\mathbf{5 0 \%}$ & Myometrial invasion $\mathbf{5 0 \%}$ & Number of patients \\
\hline Frozen & 32 & 8 & 40 \\
\hline Pathology & 29 & 11 & 40 \\
\hline
\end{tabular}


Table 4. Clinicopathological characteristics

\begin{tabular}{|c|c|c|c|c|}
\hline & \multicolumn{4}{|c|}{ Endometrial Cancer Type } \\
\hline & \multicolumn{2}{|c|}{ Endometrioid } & \multicolumn{2}{|c|}{ Non-Endometrioid } \\
\hline Number of patients & \multicolumn{2}{|c|}{$37(82 \%)$} & \multicolumn{2}{|c|}{$8(18 \%)$} \\
\hline Age, mean $( \pm$ SD) & \multicolumn{2}{|c|}{$61,35 \pm 8,99$} & \multicolumn{2}{|c|}{$63 \pm 8,08$} \\
\hline Grade & $\begin{array}{l}\text { Grade } 1 \\
\text { Grade } 2 \\
\text { Grade } 3\end{array}$ & $\begin{array}{l}24(64,8 \%) \\
7(18,9 \%) \\
6(16,3 \%)\end{array}$ & & \\
\hline Depth of myometrial invasion & $\begin{array}{l}N o \\
<50 \% \\
>50 \%\end{array}$ & $\begin{array}{l}5(14 \%) \\
20(54 \%) \\
12(32 \%)\end{array}$ & $\begin{array}{l}N o \\
<50 \% \\
>50 \%\end{array}$ & $\begin{array}{l}2(26 \%) \\
3(37 \%) \\
3(37 \%)\end{array}$ \\
\hline Peritoneal cytology & $\begin{array}{l}P C(+) \\
P C(-) \\
\text { Not clear }\end{array}$ & $\begin{array}{l}4(11 \%) \\
32(86 \%) \\
1(3 \%)\end{array}$ & $\begin{array}{l}P C(+) \\
P C(-) \\
\text { Not clear }\end{array}$ & $\begin{array}{l}0(0 \%) \\
7(88 \%) \\
1(12 \%)\end{array}$ \\
\hline LVSI & $\begin{array}{l}\operatorname{LVSI}(+) \\
\operatorname{LVSI}(-)\end{array}$ & $\begin{array}{l}9(24 \%) \\
28(76 \%)\end{array}$ & $\begin{array}{l}\operatorname{LVSI}(+) \\
\operatorname{LVSI}(-)\end{array}$ & $\begin{array}{l}3(38 \%) \\
5(72 \%)\end{array}$ \\
\hline Lymph node metastasis & $\begin{array}{l}L N(+) \\
L N(-) \\
\text { Not sampled }\end{array}$ & $\begin{array}{l}0(0 \%) \\
19(51 \%) \\
18(49 \%)\end{array}$ & $\begin{array}{l}\text { LN (+) } \\
\text { LN (-) } \\
\text { Not sampled }\end{array}$ & $\begin{array}{l}2(25 \%) \\
5(63 \%) \\
1(12 \%)\end{array}$ \\
\hline Stage & $\begin{array}{l}\text { Stage } 1 \\
\text { Stage } 2 \\
\text { Stage } 3\end{array}$ & $\begin{array}{l}28(76 \%) \\
6(16 \%) \\
3(8 \%)\end{array}$ & $\begin{array}{l}\text { Stage } 1 \\
\text { Stage } 2 \\
\text { Stage } 3\end{array}$ & $\begin{array}{l}4(50 \%) \\
1(12 \%) \\
3(38 \%)\end{array}$ \\
\hline
\end{tabular}

Table 5. ROC analysis when all patients were considered

\begin{tabular}{|l|l|l|l|}
\hline & AUC (Area under the curve) & $\mathbf{9 5 \%}$ CI & p value \\
\hline MRI & 0,842 & $0,713-0,971$ & $<\mathbf{0 0 1}$ \\
\hline HE-4 & 0,629 & $0,440-0,818$ & 0,157 \\
\hline CA-125 & 0,656 & $0,483-0,830$ & 0,087 \\
\hline USG & 0,564 & $0,372-0,756$ & 0,496 \\
\hline
\end{tabular}

Table 6. ROC analysis in endometrioid type cancer

\begin{tabular}{|l|l|l|l|}
\hline & AUC (Area under the curve) & $\mathbf{9 5 \%}$ CI & p value \\
\hline MRI & 0,840 & $0,689-0,991$ & $\mathbf{0 , 0 0 1}$ \\
\hline HE-4 & 0,737 & $0,561-0,913$ & $\mathbf{0 , 0 2 1}$ \\
\hline CA-125 & 0,717 & $0,535-0,899$ & $\mathbf{0 , 0 3 5}$ \\
\hline USG & 0,555 & $0,336-0,773$ & 0,606 \\
\hline
\end{tabular}

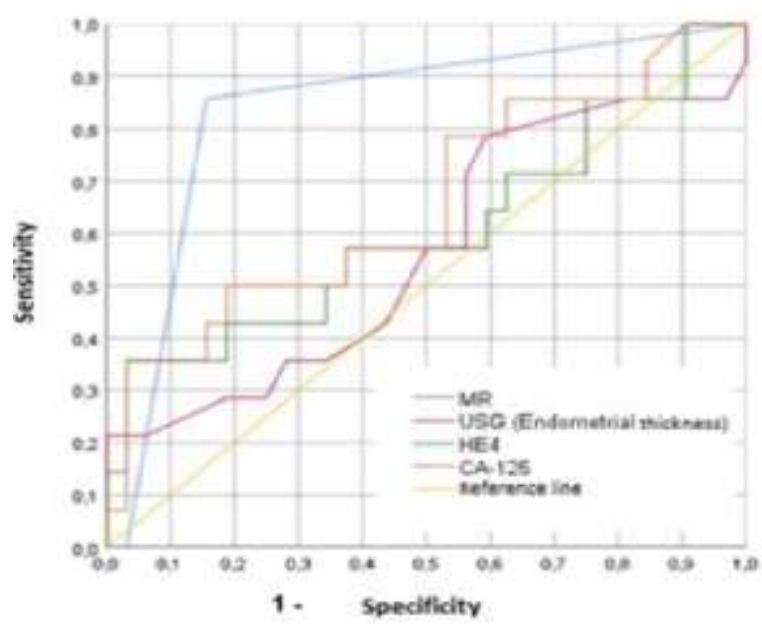

Figure 1. ROC curve for myometrial invasion depth regardless of endometrial cancer type

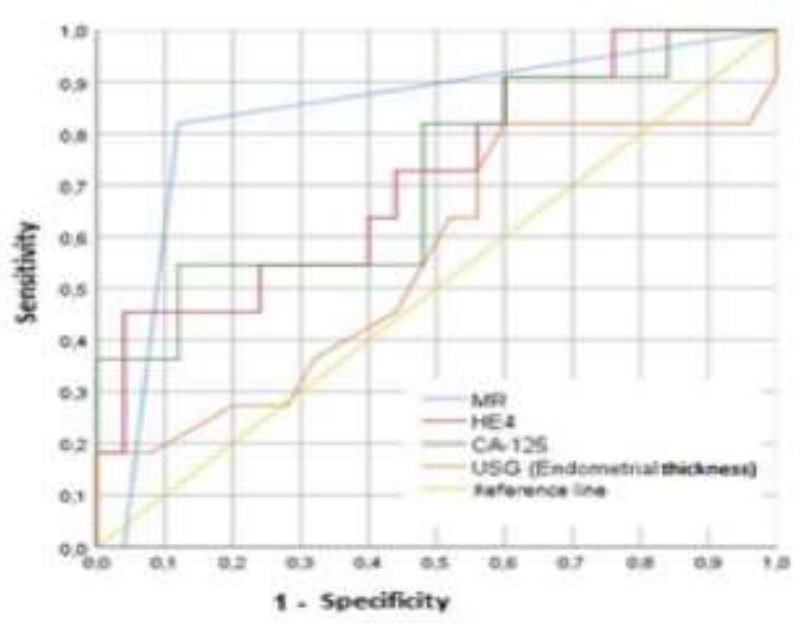

Figure 2. ROC curve for myometrial invasion depth in patients with endometrioid cancers 
Table 7. Relationship between tumor markers and the extent of the disease

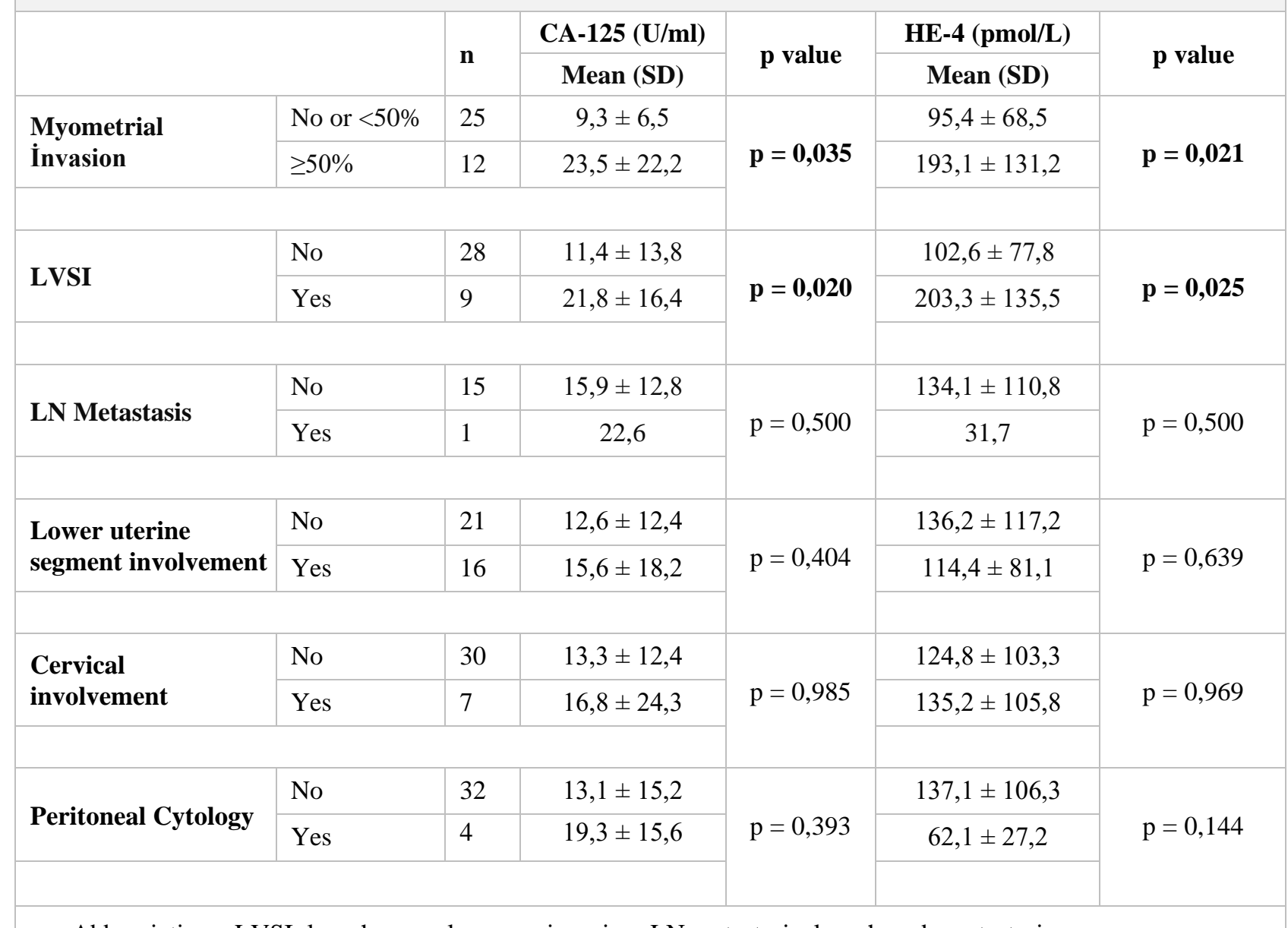

Abbreviations: LVSI, lymphovascular space invasion; LN metastasis, lymph node metastasis

According to the results of ROC analysis, the CA-125 cut-off value with the highest sensitivity and specificity in the evaluation of myometrial invasion depth was found to be $7,05 \mathrm{U} / \mathrm{ml}$. At this cut-off value, the sensitivity and specificity of CA-125 in determining the depth of myometrial invasion were $83 \%$ and $52 \%$, respectively. HE4 cut-off value with the highest sensitivity and specificity in the evaluation of myometrial invasion depth was observed as $94.25 \mathrm{pmol} / \mathrm{L}$. When this cut-off value is taken, the sensitivity of HE-4 in determining the depth of myometrial invasion was $75 \%$ and its specificity was $56 \%$. According to these results, the success rates of the tests in predicting the depth of myometrial invasion were MRI, HE-4 and CA-125, respectively. Since the total number of cases in non-endometrioid type endometrial cancers is very low, ROC analysis could not be performed for these tumors.

The relationship between the extent of the disease and serum CA-125 levels in patients with endometrioid type endometrial cancer is presented in Table 7. Serum CA-125 levels were found to be significantly higher in cases where the depth of myometrial invasion was above $50 \%$ and lymphovascular space invasion was present $(\mathrm{p}<0,05)$.
Although there was an increase in CA-125 serum levels in cases with lymph node involvement, lower uterine segment involvement, cervical involvement and positive peritoneal cytology, this increment was not statistically significant.

The relationship between the extent of the disease and serum HE-4 levels in patients with endometrioid type endometrial cancer is presented in Table 7. Similar to CA125, serum HE-4 levels were found to be significantly higher in cases where the depth of myometrial invasion was above $50 \%$ and lymphovascular space invasion was present $(p<0,05)$. Unlike CA-125, there was no relationship between serum HE-4 levels and lymph node involvement, lower uterine segment involvement, cervical involvement and positive peritoneal cytology.

Three patients had $<50 \%$ myometrial invasion according to frozen section. Even so, for these three patients, the depth of myometrial invasion was reported to be more than $50 \%$ in the final pathology report. 2 of the 3 patients had HE-4 serum levels compatible with $>50 \%$ depth of myometrial invasion, while CA-125 serum levels in all three patients were compatible with $>50 \%$ depth of myometrial invasion according to the cut-off values of 94.25 pmol/L for HE-4 and of 7.05 U/ml for CA-125. 


\section{Discussions}

Although endometrial cancer is one of the most common cancers in the world, unlike other cancer types, there is no effective screening test to predict the extent of the disease and help the surgeon planning the procedure. Imaging methods such as MRI, CT scan and ultrasonography are used for the evaluation; however, the need for a simple and cost-effective screening method still stands to be established.

CA-125, one of the tumor markers studied and shown to be effective in endometrial cancer, is a molecule secreted from tissues originating from mesothelial and coeliac epithelium (such as the peritoneum, pleura, pericardium, endometrium, endocervix and fallopian tubes). CA-125 is a marker with high sensitivity for ovarian cancer. There are studies showing an increase in the serum concentrations of CA-125 in endometrial cancer [12-14]. The increment is significant, especially in advanced stages. The standard cut-off value for CA-125 is $35 \mathrm{U} / \mathrm{ml}$. However, lower cutoff values are more sensitive to show the depth of myometrial invasion and lymph node metastasis.

In two studies, CA-125 cut-off value was taken as 20 $\mathrm{U} / \mathrm{ml}$. In one of these studies, the sensitivity and specificity of CA-125 determining the myometrial invasion were $63 \%$ and $71 \%$, respectively [15]. In the other study, the sensitivity and the specificity of CA-125 in detecting endometrial cancer patients were $70 \%$ and $71 \%$, respectively [16].

In our study, similar to the previous studies, preoperative CA-125 serum levels were found to be significantly higher in cases where the depth of myometrial invasion was above 50\% and lymphovascular space invasion was present. When the cut-off value is taken as $7,05 \mathrm{U} / \mathrm{ml}, \mathrm{CA}-125$ predicts the depth of myometrial invasion with $83 \%$ sensitivity and $52 \%$ specificity. In previous studies, it has been shown that serum CA-125 levels can increase significantly in the presence of poor prognostic factors, such as lymph node metastasis and advanced stages. We detected increased serum CA-125 levels in such cases, but the increment was not statistically significant. The reason for this may be the early-stage disease detected in most of the patients who participated in the study.

Human Epididymis Protein-4 was first shown on the distal epididymis epithelium and was discovered as a protease inhibitor involved in sperm maturation $[17,18]$. HE-4 is a member of the whey acidic protein family and is a protease inhibitor with immunoprotective effects [19]. Although the mechanism of action of HE-4 is not fully understood, it is thought that HE-4 plays an important role in cell migration, cell invasion and regulation of the extracellular matrix. After HE-4 was included in the "NCCN ovarian cancer diagnosis and treatment guidelines" in 2012, HE-4 was also started to be investigated in endometrial cancers. In their study, Moore et al. showed that serum HE-4 levels were significantly different between patients with endometrial cancer and healthy individuals [9].

Angioli et al. showed that the HE-4 level with the highest sensitivity and specificity in endometrial cancer is $70 \mathrm{pmol} / \mathrm{L}$ [11]. Later, studies have shown that the increase in pre-operative serum HE-4 levels is an independent risk factor in terms of mean survival, disease-free survival and progression-free survival. HE-4 is also helpful in predicting the need for lymph node dissection before surgery [20]. In our study, similar to the previous studies, serum HE-4 levels were found to be significantly higher in cases where the depth of myometrial invasion was more than $50 \%$. When the cutoff value was taken as $94,25 \mathrm{pmol} / \mathrm{L}$, the sensitivity and specificity of HE-4 were found to be $75 \%$ and $56 \%$. In our study, it can be seen that there is a significant relationship between the presence of lymphovascular space invasion and serum HE-4 levels.

Studies have shown that the increment in serum HE-4 levels is not associated with pathological subtypes and estrogen sensitivity [21]. The significant relationship between the depth of myometrial invasion and these two serum tumor markers in type 1 endometrial cancer disappears when a small number of type 2 endometrial cancer patients are included in the study; it is evaluated that serum HE-4 and CA-125 levels do not increase in type 2 cancer.

In the studies of Moore and Mutz-Dehbalaie, no significant relationship was found between HE-4 and the presence of lymph node metastasis $[10,22]$. However, there are many studies in the literature showing that there is a significant relationship between serum HE-4 levels and lymph node positivity [23,24]. In our study, no significant relationship was found between serum CA-125 and HE-4 levels and patients with positive lymph nodes in endometrial cancer. The reason for this may be that the sample size of the study did not consist of a large number of cases. Among the existing patients, the number of patients with positive lymph nodes is relatively few.

In previous studies, magnetic resonance imaging has been shown to have the highest sensitivity and specificity in the evaluation of the depth of myometrial invasion in endometrial cancer. In two studies, the sensitivity of MRI in predicting the depth of myometrial invasion was $84 \%$ and $89 \%$, and specificity was $71 \%$ and $100 \%$, respectively $[25,26]$. In our study, similar to the other studies, the sensitivity of magnetic resonance imaging in the evaluation of the depth of myometrial invasion in cases with endometrial cancer was $87.1 \%$ and the specificity was $86.7 \%$. 
In our study, similar to the previous studies, the most successful method in predicting the depth of myometrial invasion before the operation is magnetic resonance imaging, followed by HE-4 and CA-125, respectively. Nevertheless, measurement of serum CA-125 and HE-4 levels stands out as a valuable method in preoperative assessment of the extent of the disease in patients with endometrial cancer. Measurement of serum tumor markers is a simpler and less-costly method compared to MRI.

Evaluation by ultrasonography has not been found to have significant success in predicting the cases where the depth of myometrial invasion is above $50 \%$, and a cut-off value in terms of endometrial thickness could not be determined in ultrasonographic evaluation.

The limitations are that the MR images were evaluated by a single radiologist, the study was performed in a singlecenter, the number of patients included in our study was relatively low, and the patient distribution was not homogeneous in terms of stage, lymph node metastasis, lower uterine segment involvement, lymphovascular space invasion, and endometrial cancer types.

The strengths of our study are that it is a prospective study. In addition, both MRI and serum markers were used in the same patient during the evaluation, and the success of different examinations was evaluated in the same patient. In similar studies in the literature, imaging methods, serum tumor markers and their combinations were compared among themselves in evaluating the severity of the disease. For our knowledge, our study is the first study comparing the success of imaging methods and serum tumor markers to each other in evaluating the extent of the disease, and this is one of the strengths of our study.

\section{Conclusions}

Although magnetic resonance imaging is still the best examination for the pre-operative prediction of endometrial cancer spread and myometrial invasion depth, in this study, it has been clearly shown that measuring CA125 and HE-4 serum levels are simpler and less costly methods and can be used for preoperative evaluation. It should be kept in mind that, in further studies with higher populations and better distribution of stages and endometrial cancer types, more successful results can be obtained in the use of these serum markers alone or in combination with each other.

\section{Conflict of interest disclosure}

There are no known conflicts of interest in the publication of this article. The manuscript was read and approved by all authors.

\section{Compliance with ethical standards}

Any aspect of the work covered in this manuscript has been conducted with the ethical approval of all relevant bodies and that such approvals are acknowledged within the manuscript.

\section{References}

1. Bray F, Ferlay J, Soerjomataram I, Siegel RL, Torre LA, Jemal A. Global cancer statistics 2018: GLOBOCAN estimates of incidence and mortality worldwide for 36 cancers in 185 countries. CA Cancer J Clin. 2018;68(6):394-424. doi: 10.3322/caac. 21492

2. Ferlay J, Soerjomataram I, Dikshit R, Eser S, Mathers C, Rebelo M, Parkin DM, Forman D, Bray F. Cancer incidence and mortality worldwide: sources, methods and major patterns in GLOBOCAN 2012. Int J Cancer. 2015;136(5):E359-86. doi: 10.1002/ijc.29210

3. Torres ML, Weaver AL, Kumar S, Uccella S, Famuyide AO, Cliby WA, Dowdy SC, Gostout BS, Mariani A. Risk factors for developing endometrial cancer after benign endometrial sampling. Obstet Gynecol. 2012;120(5):9981004. doi: 10.1097/aog.0b013e31826b9fef

4. Andreano A, Rechichi G, Rebora P, Sironi S, Valsecchi MG, Galimberti S. MR diffusion imaging for preoperative staging of myometrial invasion in patients with endometrial cancer: a systematic review and metaanalysis. Eur Radiol. 2014;24(6):1327-38. doi: 10.1007/s00330-014-3139-4

5. Seagle BL, Alexander AL, Lantsman T, Shahabi S. Prognosis and treatment of positive peritoneal cytology in early endometrial cancer: matched cohort analyses from the National Cancer Database. Am J Obstet Gynecol. 2018;218(3):329.e1-329.e15. doi: 10.1016/j.ajog.2017.11.601

6. Mariani A, Dowdy SC, Cliby WA, Gostout BS, Jones MB, Wilson TO, Podratz KC. Prospective assessment of lymphatic dissemination in endometrial cancer: a paradigm shift in surgical staging. Gynecol Oncol. 2008;109(1):11-8. doi: 10.1016/j.ygyno.2008.01.023

7. Baser E, Gungor T, Togrul C, Turkoglu O, Celen S. Preoperative prediction of poor prognostic parameters and adjuvant treatment in women with pure endometrioid type endometrial cancer: what is the significance of tumor markers? Eur J Gynaecol Oncol. 2014;35(5):513-8.

8. Schummer M, Ng WV, Bumgarner RE, Nelson PS, Schummer B, Bednarski DW, Hassell L, Baldwin RL, Karlan BY, Hood L. Comparative hybridization of an array of 21,500 ovarian cDNAs for the discovery of genes overexpressed in ovarian carcinomas. Gene. 1999;238(2):375-85. doi: 10.1016/s0378-1119(99)00342-x

9. Moore RG, Brown AK, Miller MC, Skates S, Allard WJ, Verch T, Steinhoff M, Messerlian G, DiSilvestro P, Granai CO, Bast RC Jr. The use of multiple novel tumor biomarkers for the detection of ovarian carcinoma in 
patients with a pelvic mass. Gynecol Oncol. 2008;108(2):402-8. doi: 10.1016/j.ygyno.2007.10.017

10. Moore RG, Miller CM, Brown AK, Robison K, Steinhoff M, Lambert-Messerlian G. Utility of tumor marker HE4 to predict depth of myometrial invasion in endometrioid adenocarcinoma of the uterus. Int $J$ Gynecol Cancer. 2011;21(7):1185-90. doi: 10.1097/IGC.0b013e3182229ad8

11. Angioli R, Plotti F, Capriglione S, Montera R, Damiani P, Ricciardi R, Aloisi A, Luvero D, Cafà EV, Dugo N, Angelucci M, Benedetti-Panici P. The role of novel biomarker HE4 in endometrial cancer: a case control prospective study. Tumour Biol. 2013;34(1):571-6. doi: 10.1007/s13277-012-0583-0

12. Sebastianelli A, Renaud MC, Grégoire J, Roy M, Plante M. Preoperative CA 125 tumour marker in endometrial cancer: correlation with advanced stage disease. $J$ Obstet Gynaecol Can. 2010;32(9):856-860. doi: 10.1016/S1701-2163(16)34657-6

13. Hsieh $\mathrm{CH}$, ChangChien CC, Lin H, Huang EY, Huang CC, Lan KC, Chang SY. Can a preoperative CA 125 level be a criterion for full pelvic lymphadenectomy in surgical staging of endometrial cancer? Gynecol Oncol. 2002;86(1):28-33. doi: 10.1006/gyno.2002.6664

14. Chung HH, Kim JW, Park NH, Song YS, Kang SB, Lee HP. Use of preoperative serum CA-125 levels for prediction of lymph node metastasis and prognosis in endometrial cancer. Acta Obstet Gynecol Scand. 2006;85(12):1501-5. doi: 10.1080/00016340601022777

15. Kurihara T, Mizunuma H, Obara M, Andoh K, Ibuki Y, Nishimura T. Determination of a normal level of serum CA125 in postmenopausal women as a tool for preoperative evaluation and postoperative surveillance of endometrial carcinoma. Gynecol Oncol. 1998;69(3): 192-6. doi: 10.1006/gyno.1998.5018

16. Dotters DJ. Preoperative CA 125 in endometrial cancer: is it useful? Am J Obstet Gynecol. 2000;182(6):1328-34. doi: 10.1067/mob.2000.106251

17. Kirchhoff C, Habben I, Ivell R, Krull N. A major human epididymis-specific cDNA encodes a protein with sequence homology to extracellular proteinase inhibitors. Biol Reprod. 1991;45(2):350-7. doi: 10.1095/biolreprod45.2.350

18. Kirchhoff C. Molecular characterization of epididymal proteins. Rev Reprod. 1998;3(2):86-95. doi: 10.1530/ror.0.0030086
19. Bingle L, Singleton V, Bingle CD. The putative ovarian tumour marker gene HE4 (WFDC2), is expressed in normal tissues and undergoes complex alternative splicing to yield multiple protein isoforms. Oncogene. 2002;21(17):2768-73. doi: 10.1038/sj.onc. 1205363

20. Zanotti L, Bignotti E, Calza S, Bandiera E, Ruggeri G, Galli C, Tognon G, Ragnoli M, Romani C, Tassi RA, Caimi L, Odicino FE, Sartori E, Pecorelli S, Ravaggi A. Human epididymis protein 4 as a serum marker for diagnosis of endometrial carcinoma and prediction of clinical outcome. Clin Chem Lab Med. 2012; 50(12):2189-98. doi: 10.1515/cclm-2011-0757

21. Li X, Gao Y, Tan M, Zhuang H, Gao J, Hu Z, Wang H, Zhu L, Liu J, Lin B. Expression of HE4 in Endometrial Cancer and Its Clinical Significance. Biomed Res Int. 2015;2015:437468. doi: 10.1155/2015/437468

22. Mutz-Dehbalaie I, Egle D, Fessler S, Hubalek M, Fiegl $\mathrm{H}$, Marth C, Widschwendter A. HE4 is an independent prognostic marker in endometrial cancer patients. Gynecol Oncol. 2012;126(2):186-91. doi: 10.1016/j.ygyno.2012.04.022

23. Bignotti E, Ragnoli M, Zanotti L, Calza S, Falchetti M, Lonardi S, Bergamelli S, Bandiera E, Tassi RA, Romani C, Todeschini P, Odicino FE, Facchetti F, Pecorelli S, Ravaggi A. Diagnostic and prognostic impact of serum HE4 detection in endometrial carcinoma patients. Br J Cancer. 2011;104(9):1418-25. doi: 10.1038/bjc.2011.109

24. Antonsen SL, Høgdall E, Christensen IJ, Lydolph M, Tabor A, Loft Jakobsen A, Fagö-Olsen CL, Andersen ES, Jochumsen K, Høgdall C. HE4 and CA125 levels in the preoperative assessment of endometrial cancer patients: a prospective multicenter study (ENDOMET). Acta Obstet Gynecol Scand. 2013;92(11):1313-22. doi: 10.1111/aogs. 12235

25. Savelli L, Ceccarini M, Ludovisi M, Fruscella E, De Iaco PA, Salizzoni E, Mabrouk M, Manfredi R, Testa AC, Ferrandina G. Preoperative local staging of endometrial cancer: transvaginal sonography vs. magnetic resonance imaging. Ultrasound Obstet Gynecol. 2008;31(5):560-6. doi: 10.1002/uog.5295

26. Vasconcelos C, Félix A, Cunha TM. Preoperative assessment of deep myometrial and cervical invasion in endometrial carcinoma: comparison of magnetic resonance imaging and histopathologic evaluation. $J$ Obstet Gynaecol. 2007;27(1):65-70. doi: $10.1080 / 01443610601056418$ 